\title{
Brain metastases from breast cancer: prognostic significance of HER-2 overexpression, effect of trastuzumab and cause of death
}

Romuald Le Scodan ${ }^{1,2^{*}}$, Ludivine Jouanneau ${ }^{3}$, Christophe Massard ${ }^{6}$, Maya Gutierrez ${ }^{4}$, Youlia Kirova ${ }^{2}$, Pascal Cherel ${ }^{5}$, Julie Gachet ${ }^{4}$, Alain Labib ${ }^{2}$ and Emmanuelle Mouret-Fourme ${ }^{3}$

\begin{abstract}
Background: To access the prognostic significance of HER-2 overexpression, the effect of trastuzumab and the cause of death in patients with brain metastases (BM) from breast cancer (BC).

Methods: We analyzed the outcome of 130 patients with BM from BC who received whole-brain radiotherapy (WBRT) (without surgery or radiosurgery) between January 1998 and April 2006. Demographic data, tumor characteristics, and treatments were prospectively recorded. The impact of HER-2 overexpression and trastuzumabbased therapy on overall survival (OS) and the cause of death were evaluated.

Results: The median follow-up for the whole population was 6.25 months (mean: 9.15; range: 0.23-53). The median survival time and 1-year survival rates after BM diagnosis were 7.43 months and 35.8\% (95\% Cl: 28-45.7) respectively. The median survival time for HER-2 negative patients $(n=78)$, HER-2 positive patients not treated with trastuzumab $(n=20)$ and HER-2 positive patients treated with trastuzumab $(n=32)$ were 5.9 months, 5.6 months and 19.53 months, respectively. The 1 -year survival rates were $26.1 \%, 29.2 \%$ and $62.6 \%$ respectively, $(p<0.004)$. Among the 18 HER-2 positive patients treated with trastuzumab who died, 11 (61\%) apparently succumbed from CNS progression, in the face of stable or responsive non-CNS disease. Trastuzumab-based therapy was associated with a $51 \%$ reduction in the risk of death (multiadjusted hazard ratio: 0.49; 95\% Cl, 0.29-0.83).
\end{abstract}

Conclusions: In our experience, trastuzumab-based therapy for HER-overexpressing tumors was associated with improved survival in BM BC patients. This subgroup of patients may benefit from innovative approaches, in order to obtain better intra cerebral control.

Keywords: brain metastases, breast cancer, trastuzumab, whole brain radiation therapy

\section{Background}

About $10 \%$ to $30 \%$ of patients with metastatic breast cancer develop brain metastases (BM) [1]. Several reports suggest that the risk of developing $\mathrm{BM}$ is higher (25\% to $40 \%$ ] in patients receiving trastuzumab-based therapy for HER2-overexpressing metastatic breast cancer [2-9]. Whole-brain radiotherapy (WBRT] is considered the standard treatment for most patients, particularly those with extensive intra-cranial disease, providing symptom relief and prolonging both median

\footnotetext{
* Correspondence: rlescodan@vivalto-sante.com

'Department of Radiation Oncology, Centre Hospitalier Privé Saint Grégoire, Saint Grégoire, France

Full list of author information is available at the end of the article
}

and overall survival (1,10-12). Despite the use of WBRT, the prognosis of patients with BM remains poor, with a median survival time of approximately 5 months [1,10-14]. Recent studies have examined the influence of patient characteristics on survival in this setting and have attempted to identify subgroups of patients with substantially different outcomes in order to tailor therapy and to rationalize the design, stratification and interpretation of clinical trials [13-19]. The Radiation Therapy Oncology Group (RTOG] recursive partitioning analysis (RPA) classification based on clinical factors (Karnofsky performance status, age, and control of extracerebral disease) is a major prognostic indicator for patients with brain metastases [13]. Several reports

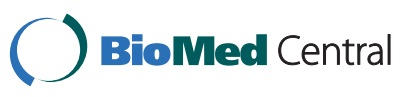


suggest that trastuzumab-treated HER2-positive breast cancer patients with BM fare better than HER2-negative breast cancer patients and patients with HER2-positive tumors who do not receive trastuzumab [20-26]. The prognostic significance of HER-2 overexpression and trastuzumab-based therapy has not been analyzed in the previously published prognostic scores of patients with brain metastases. The aim of this study was to confirm, in a cohort of patients with BM from breast carcinoma, the beneficial effect of trastuzumab in patients with HER2-positive disease, and to analyze the cause of death.

\section{Methods}

\section{Patients and treatments}

Between January 1998 and April 2006, 195 consecutive breast cancer patients with BM were treated at Institut Curie-Hôpital René Huguenin Cancer Center, Saint Cloud, France. The study population consisted of 130 patients who received whole brain radiation therapy (WBRT) (without surgery or radiosurgery) and whose tumoral HER-2 status was known. The characteristics of these 130 patients, their tumors, metastatic sites, and therapy (chemotherapy, endocrine therapy or trastuzumab-based therapy) were prospectively recorded in the hospital's MEDICOD database. Karnofsky performance status (KPS) (<70 vs $\geq 70$ ), the Radiation Therapy Oncology Group (RTOG) recursive partition analysis (RPA) class (I-II vs III) [13] and the number of BM (single vs multiple) at the time of BM diagnosis were obtained retrospectively from the medical charts. The primary tumor was considered to be HER-2-positive (HER-2+) if it scored $3+$ on immunohistochemistry (IHC), or if it scored $2+$ on IHC and showed gene amplification by fluorescence in situ hybridization (FISH). Trastuzumab exposure for metastatic disease before and after BM diagnosis was recorded. All the patients had computed tomography (CT) and/or magnetic resonance imaging (MRI) for BM diagnosis. WBRT was delivered with a standardized lateral opposed fields technique that used 6-MV or 10-MV photons, up to a standard dose of 30 Gy in ten daily 3Gy fractions. The patients were seen every month for 6 months after the end of treatment, and then every 2 months. Our institutional review board approved the acquisition, analysis and reporting of the patients' data.

\section{Statistical analysis}

Patient characteristics were compared by using the chisquare test or Ficher's exact test for categorical variables and by using the T-test or Kruskall Wallis test for the quantitative variables. Overall survival was defined as the time from BM diagnosis to the last visit or death. Survival curves were constructed with the Kaplan Meier method [27] and compared with the log-rank test. Multivariate analysis (Cox regression model) tested the following variables for their impact on overall survival: age at BM diagnosis, KPS ( $<70$ vs $\geq 70$ ), RTOG RPA class (I-II vs III), presence of extracranial metastases, sites of other extracranial metastases (bone vs lung vs liver vs multiple), number of BM (single vs multiple), interval between primary tumor and BM diagnosis $(<2$ years vs $>2$ years), tumor HR status, lymphocyte count at BM diagnosis $\left(<0.7\right.$ vs $\left.>0.7 \times 10^{9} / \mathrm{L}\right)$, HER-2 overexpression and trastuzumab-based therapy. First, the variables were obtained in univariate analysis. Then, the multivariate model was computed with backward step. Differences with $\mathrm{P}$ values $<0.05$ were considered statistically significant.

\section{Results}

\section{Patient characteristics and treatments}

The characteristics of the 130 eligible patients are reported in table 1 . Briefly, mean age at diagnosis was 52.8 years (median: 52; range: $26-83$ ), and 54 patients (41.5\%) were younger than 50 years. The KPS was $\geq 70$ in $62.2 \%$ of cases. The median time from breast cancer diagnosis to BM diagnosis was 40.6 months (range, 0265 months). Fifty-two patients $(40 \%)$ had tumors that overexpressed Her-2, and 32 patients had received trastuzumab-based therapy in the metastatic setting. Patients treated before 2001 were not systematically treated with trastuzumab. Of these $32 \mathrm{pts}, 5$ pts stopped trastuzumab before the diagnosis of BM because of systemic progression, 5 discontinued trastuzumab at the diagnosis of BM and 22 continued a trastuzumab-based therapy after WBRT.

At BM diagnosis, patients with HER2-overexpressing breast cancer treated with trastuzumab-based therapy ( $\mathrm{n}$ = 32), compared with HER-2 negative patients $(\mathrm{n}=78)$ and HER-2 positive patients not treated with trastuzumab-based therapy $(n=20)$, were younger (median age: 47 vs 54 and 53 , respectively; $\mathrm{p}=0.01$ ), had a better Karnofsky performance status (KPS $\geq 70: 80.6 \%$ vs $57.9 \%$ vs $50 \%$, respectively; $\mathrm{p}=0.04$ ) and were thus less likely to be RTOG RPA class III, were more likely to have liver metastases $(71.88 \%$ vs $44.87 \%$ vs $60 \%$, respectively; $\mathrm{p}=0.02$ ) and were more likely to have received chemotherapy, including taxane-based chemotherapy, for metastatic breast cancer, respectively (table 1). The median dose of WBRT was $30 \mathrm{~Gy}$, in ten 3-Gy daily fractions (mean, $28.1 \mathrm{~Gy}$; range, 3-40 Gy), distributed as follows: 112 patients received 30 Gy in 10 fractions; 13 patients received < 30 Gy in 3-Gy daily fractions; and 5 patients received $>30$ Gy in 2-Gy daily fractions. All but 13 of the patients completed the full course of WBRT; these 13 patients discontinued treatment because of deteriorating systemic or brain disease. Most 
Table 1 patient characteristics at diagnosis of brain metastases and treatments

\begin{tabular}{|c|c|c|c|c|c|}
\hline $\begin{array}{l}\text { Patient and tumor } \\
\text { characteristics }\end{array}$ & $\begin{array}{l}\text { HER-2 negative } \\
\text { patients } \\
\begin{array}{c}N=78 \\
-60 \%\end{array}\end{array}$ & $\begin{array}{l}\text { HER-2 positive patients not } \\
\text { treated with trastuzumab } \\
\qquad \begin{array}{c}\mathrm{N}=20 \\
-15.38 \%\end{array}\end{array}$ & $\begin{array}{l}\text { HER-2 positive patients treated } \\
\text { with trastuzumab } \\
N=32 \\
-24.62 \%\end{array}$ & $\begin{array}{c}\text { Whole } \\
\text { population } \\
N=130\end{array}$ & $P$ value \\
\hline \multicolumn{6}{|c|}{$\begin{array}{l}\text { Age at BM diagnosis (years)- } \\
\text { median (range) }\end{array}$} \\
\hline$<65$ years & $54(34-83)$ & $53(33-75)$ & $47(26-67)$ & $52(26-83)$ & 0.0178 \\
\hline \multirow[t]{2}{*}{$\geq 65$ years } & $59 / 77(76.62)$ & $15 / 20(75)$ & $31 / 32(96.88)$ & $\begin{array}{l}105 / 129 \\
(81.4)\end{array}$ & \\
\hline & 18/77 (23.38) & $5 / 20(25)$ & $1 / 32(3.12)$ & $\begin{array}{c}24 / 129 \\
(18.6)\end{array}$ & \\
\hline \multicolumn{6}{|l|}{$\begin{array}{l}\text { Karnofsky performance } \\
\text { status }\end{array}$} \\
\hline$<70$ & $32 / 76(42.11)$ & $10 / 20(50)$ & 6/31 (19.35) & $\begin{array}{c}48 / 127 \\
(37.8)\end{array}$ & 0.0418 \\
\hline$\geq 70$ & 44/76 (57.89) & 10/20 (50) & 25/31 (80.65) & $\begin{array}{c}79 / 127 \\
(62.2)\end{array}$ & \\
\hline RTOG RPA class & 0 & 0 & 0 & 0 & 0.0391 \\
\hline । & $43 / 75(57.33)$ & $10 / 20(50)$ & $25 / 31(80.65)$ & $\begin{array}{c}78 / 126 \\
(61.9)\end{array}$ & \\
\hline$\|$ & $32 / 75(42.67)$ & $10 / 20(50)$ & 6/31 (19.35) & $\begin{array}{c}48 / 126 \\
(38.1)\end{array}$ & \\
\hline \multicolumn{6}{|l|}{ III } \\
\hline \multicolumn{6}{|c|}{ Histology of primary BC } \\
\hline Ductal & 70/76 (92.11) & 19/20 (95) & $30 / 32$ (93.75) & $\begin{array}{c}119 / 128 \\
(92.97)\end{array}$ & $\begin{array}{c}0.5172^{* *} \\
\text { (ns) }\end{array}$ \\
\hline Lobular & $2 / 76(2.63)$ & 0 & $2 / 32(6.25)$ & $4 / 128(3.12)$ & \\
\hline Other & $4 / 76(5.26)$ & $1 / 20(5)$ & 0 & $5 / 128(3.91)$ & \\
\hline \multicolumn{6}{|l|}{ Histologic grade } \\
\hline SBR I & $2 / 70(2.86)$ & $1 / 17(5.88)$ & 1/31 (3.23) & 4/118 (3.39) & $\begin{array}{l}0.063^{* *} \\
\text { (ns) }\end{array}$ \\
\hline SBR ॥ & $27 / 70$ (38.57) & $1 / 17(5.88)$ & $11 / 31(35.48)$ & $\begin{array}{l}39 / 118 \\
(33.05)\end{array}$ & \\
\hline SBRIII & $41 / 70(58.57)$ & 15/17 (88.24) & 19/31 (61.29) & $\begin{array}{l}75 / 118 \\
(63.56)\end{array}$ & \\
\hline \multicolumn{6}{|l|}{ Tumor HR status } \\
\hline Positive & 48/76 (63.16) & 9/19 (47.37) & $17 / 32(53.12)$ & $\begin{array}{l}72 / 127 \\
(56.69)\end{array}$ & $\begin{array}{l}0.1996 \\
\text { (ns) }\end{array}$ \\
\hline Negative & $28 / 76(36.84)$ & $10 / 19(52.63)$ & $15 / 32(46.88)$ & $\begin{array}{l}55 / 127 \\
(43.31)\end{array}$ & \\
\hline \multicolumn{6}{|l|}{ Number of BM } \\
\hline Single & 6/78 (7.69) & 0 & 0 & $6 / 130(4.62)$ & $\begin{array}{l}0.1339^{* *} \\
\text { (ns) }\end{array}$ \\
\hline Multiple & 72/78 (92.31) & $20 / 20(100)$ & $32 / 32(100)$ & $\begin{array}{l}124 / 130 \\
(95.38)\end{array}$ & $\begin{array}{c}0.1778 \text { ** } \\
\text { (ns) }\end{array}$ \\
\hline Meningitis & 17/77 (22.08) & $1 / 20(5)$ & $4 / 31(12.9)$ & $\begin{array}{l}22 / 128 \\
(17.19)\end{array}$ & \\
\hline Yes & 60/77 (77.92) & $19 / 20(95)$ & $27 / 31(87.1)$ & $\begin{array}{l}106 / 128 \\
(82.81)\end{array}$ & \\
\hline \multicolumn{6}{|l|}{ No } \\
\hline \multicolumn{6}{|c|}{$\begin{array}{l}\text { Number of other metastatic } \\
\text { sites }\end{array}$} \\
\hline 0 (BM alone) & 6/78 (7.69) & $1 / 20(5)$ & 0 & 7/130 (5.38) & $\begin{array}{l}0.2971^{* *} \\
\text { (ns) }\end{array}$ \\
\hline 1 & $19 / 78(24.36)$ & $3 / 20(15)$ & 9/32 (28.12) & $\begin{array}{l}31 / 130 \\
(23.85)\end{array}$ & \\
\hline 2 & 20/78 (25.64) & $7 / 20$ (35) & $14 / 32(43.75)$ & $\begin{array}{l}41 / 130 \\
(31.54)\end{array}$ & \\
\hline
\end{tabular}


Table 1 patient characteristics at diagnosis of brain metastases and treatments (Continued)

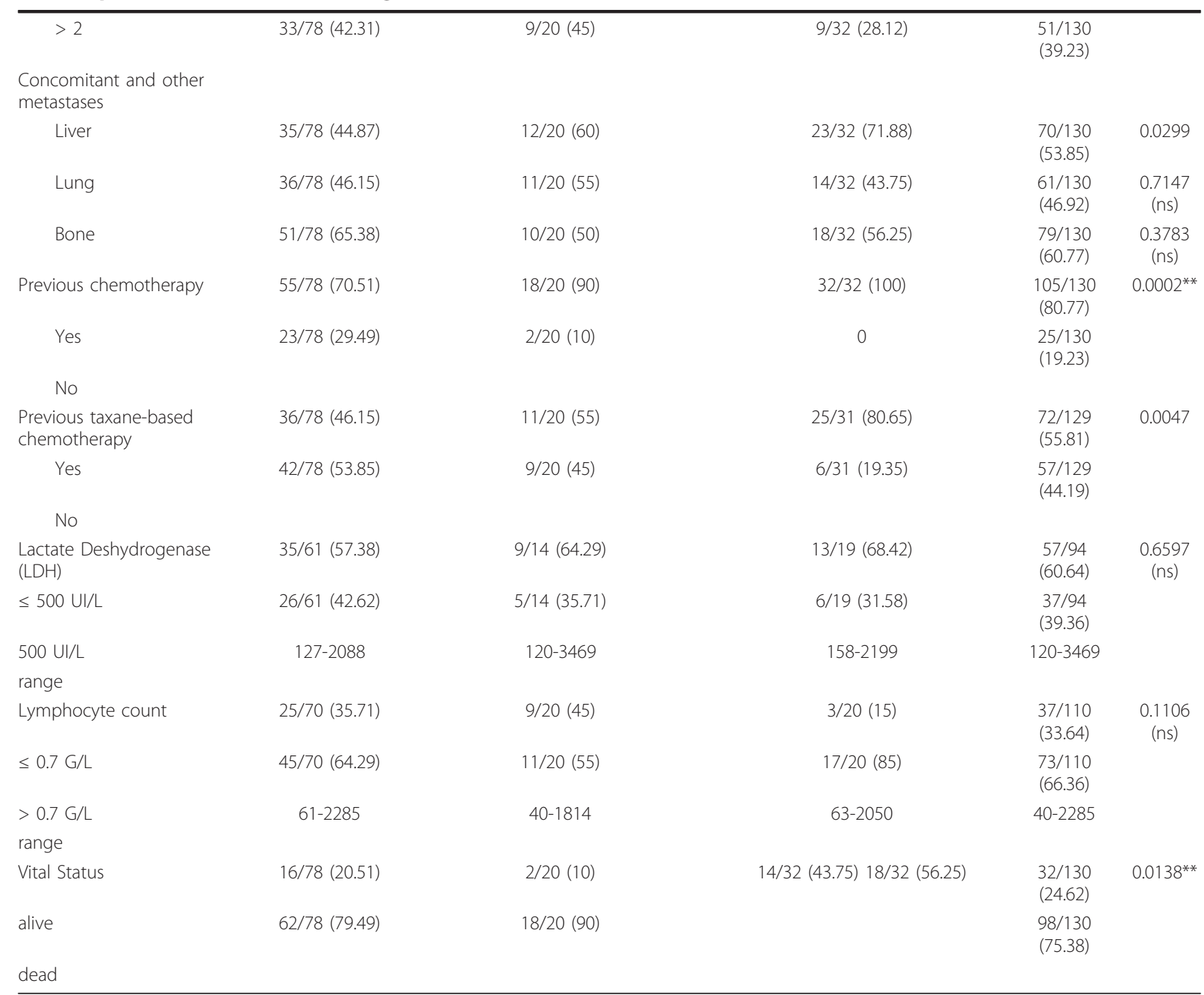

Abbreviations: BM = brain metastases; BC = breast cancer; SBR = Scarff-Bloom-Richardson grade; HR = hormone receptor; RTOG = Radiation

** Fisher's exact test

Values are numbers (percentage), unless otherwise stated.

patients received corticosteroids before WBRT started. Chemotherapy had been administered to $105(80.8 \%)$ patients before BM diagnosis.

\section{Patient outcomes}

The median follow-up for the whole population was 6.25 months (mean: 9.15; range: 0.23-53). Ninety-eight patients died $(75.4 \%)$. The median survival time and the 6-month and 1-year survival rates after BM diagnosis were 7.43 months (95\% CI: 5.52-9.73), 54.9\% (95\% CI:46.8-64.3) and 35.8\% (95\% CI: 28-45.7) respectively. The median survival time among the 79 patients in RPA Class I-II at BM diagnosis was 9.63 months [95\% CI: 7.69; 15.72], compared with 3.52 months [95\% CI: 2.86; 7.36] among the 48 patients in Class III ( $\mathrm{p}=0.001]$. The median survival time for HER-2 negative patients ( $\mathrm{n}=$ 78), HER-2 positive patients not treated with trastuzumab $(\mathrm{n}=20)$ and HER-2 positive patients treated with trastuzumab $(\mathrm{n}=32)$ were 5.9 months, 5.6 months and 19.53 months respectively. The 1-year survival rates were $26.1 \%$ (95\% CI: 16.8-40.7), 29.2\% (95\% CI:17-50.2) and and 62.6\% (95\% CI: 47.2-83) respectively, ( $\mathrm{p}<$ 0.004) (Table 2, Figure 1). The median survival time for the 10 HER-2 positive patients who stopped trastuzumab before or after the diagnosis of BM and the 22 patients who continued a trastuzumab-based therapy after WBRT were 9.2 months and 20.9 months respectively ( $\mathrm{p}>0.1)$. The 1-year survival rates were $43.6(95 \%$ CI: 21.8-87.4) and 87.1 (95\% CI: 71.8-100), respectively $(\mathrm{p}=0.13)$. 
Table 2 Rates of overall survival at 6 months and 1 year according to the RTOG RPA class, the HER-2 status and the delivery of trastuzumab

\begin{tabular}{|c|c|c|c|c|c|}
\hline & $\mathrm{n}$ & $\begin{array}{l}\text { Median Survival } \\
\text { (months) }\end{array}$ & $\begin{array}{c}6 \text { months } \\
\text { [Cl95\%] }\end{array}$ & $\begin{array}{c}1 \text { year } \\
\text { [CI95\%] }\end{array}$ & $P$ value \\
\hline Whole population & 130 & $7.43(5.52-9.73)$ & $54.9[46.8 ; 64.3]$ & $35.8[28 ; 45.7]$ & \\
\hline RTOG RPA & & & & $44.6[34.3 ; 58.1]$ & 0.001 \\
\hline Class I-II & 78 & $9.63(7.69-15.72)$ & $65.9[56 ; 77.5]$ & $23.9[14.2 ; 40.4]$ & \\
\hline \multirow[t]{2}{*}{ Class III } & 48 & $3.52(2.86-7.36)$ & $37.7[26 ; 54.7]$ & & \\
\hline & & & & & 0.004 \\
\hline HER-2 negative patients & 78 & $5.88[3.75 ; 9.63]$ & $48.7[37.7 ; 63]$ & $26.1[16.8 ; 40.7]$ & \\
\hline HER-2 positive patients not treated with trastuzumab & 20 & $5.65[2.60 ; 12.49]$ & $45.5[31.3 ; 66.1]$ & $29.2[17-50.2]$ & \\
\hline HER-2 positive patients treated with trastuzumab & 32 & $19.53[9.27 ; \mathrm{NA}]$ & $77.1[63.5 ; 93.6]$ & $62.6[47.2 ; 83]$ & \\
\hline Trastuzumab & 10 & $9.17(5.52-\mathrm{NA})$ & $63.6[40.7 ; 99.5]$ & $43.6[21.8 ; 87.4]$ & 0.113 \\
\hline Stopped & 22 & $20.91(19.53-N A)$ & $94.4[84.4 ; 100]$ & $88.5[74.8 ; 100]$ & \\
\hline Continued & & & & & \\
\hline
\end{tabular}

In univariate analysis, KPS $<70$ or RTOG RPA Class III, trastuzumab-based therapy for HER-2-overexpressing tumors, a triple-negative phenotype, Scarff-BloomRichardson grade, the serum LDH level and the lymphocyte count at BM diagnosis were predictive of overall survival (Table 3). The following characteristics had no prognostic value: number of $\mathrm{BM}$, sites of other systemic metastases, interval between primary tumor and BM diagnosis, total dose of WBRT, and histology of the primary breast tumor. Trastuzumab-based therapy for HER-2-overexpressing tumors and RTOG RPA Class III or KPS $<70$ emerged as independent prognostic factors in multivariate analysis (table 4). Trastuzumab -based therapy was associated with a $51 \%$ reduction in the risk of death (multiadjusted hazard ratio [HR] 0.49; 95\% CI, 0.29 to 0.83 ].

\section{Response to WBRT and cause of death}

Among the 32 HER-2 positive patients treated with trastuzumab, only 23 pts had at least one follow-up brain CT scan or MRI by which the radiographic response could be assessed. Ten patients had CNS progression and 13 patients had stable intracerebral disease at last follow-up. The mean PFS in the brain, calculated from the date of WBRT to the date of brain progression, was 7.4 months (range: 1-18). Among the 18 HER-2 positive patients treated with trastuzumab who died, 11 (61\%) apparently succumbed from CNS progression, in the face of stable or responsive non-CNS disease. Only 6 HER2 positive BC patients treated without trastuzumab and 30 HER-2 negative patients had at least one folloxup brain CT scan.

\section{Discussion}

Because several subgroups of metastatic breast cancer patients are at a high risk of developing BM $[5,9]$ and because systemic therapy, particularly trastuzumab, has limited efficacy for preventing or controlling intracranial metastases, BM are becoming a major issue in this setting, being associated with poor survival and quality of life $[28,29]$. Risk factors for the development of CNS metastases from breast cancer include patient characteristics, such as young age and African-American ethnicity, and biological features of the tumor, including ERnegativity, HER2-positivity, high tumor grade, and BRCA1 phenotype [1,7,30-32]. Breast cancer patients with brain metastases form a heterogeneous population with respect to their prognosis [14,20-26]. Identification of patient subgroups with substantially different outcomes is therefore necessary to tailor therapy and to help with the design, stratification and interpretation of future clinical trials. The RTOG RPA classification is currently recognized as a major prognostic indicator in patients with brain metastases. It comprises three prognostic classes based on Karnofsky performance status, age, and control of extracerebral disease [13]. In this classification, the best survival (RPA Class I), with a median of 7.1 months, was observed in patients younger than 65 years of age with a KPS of at least 70, a controlled primary tumor, and metastases restricted to the brain. The worst survival (RPA Class III), with a median of 2.3 months, was seen in patients with a KPS below 70. The remaining patients (RPA Class II) had a median survival of 4.2 months. Several other prognostic scores for patients with brain metastases from different primaries [14-19] were subsequently developed, but none of them include molecular features or breast cancer-specific parameters such as tumor HER-2 overexpression, nor specific treatments.

Several groups have published retrospective studies describing improved survival from time of BM diagnosis in BM patients with HER2-positive BC treated with trastuzumab, compared with HER2-negative breast cancers [20-26]. In a retrospective study including 56 patients 


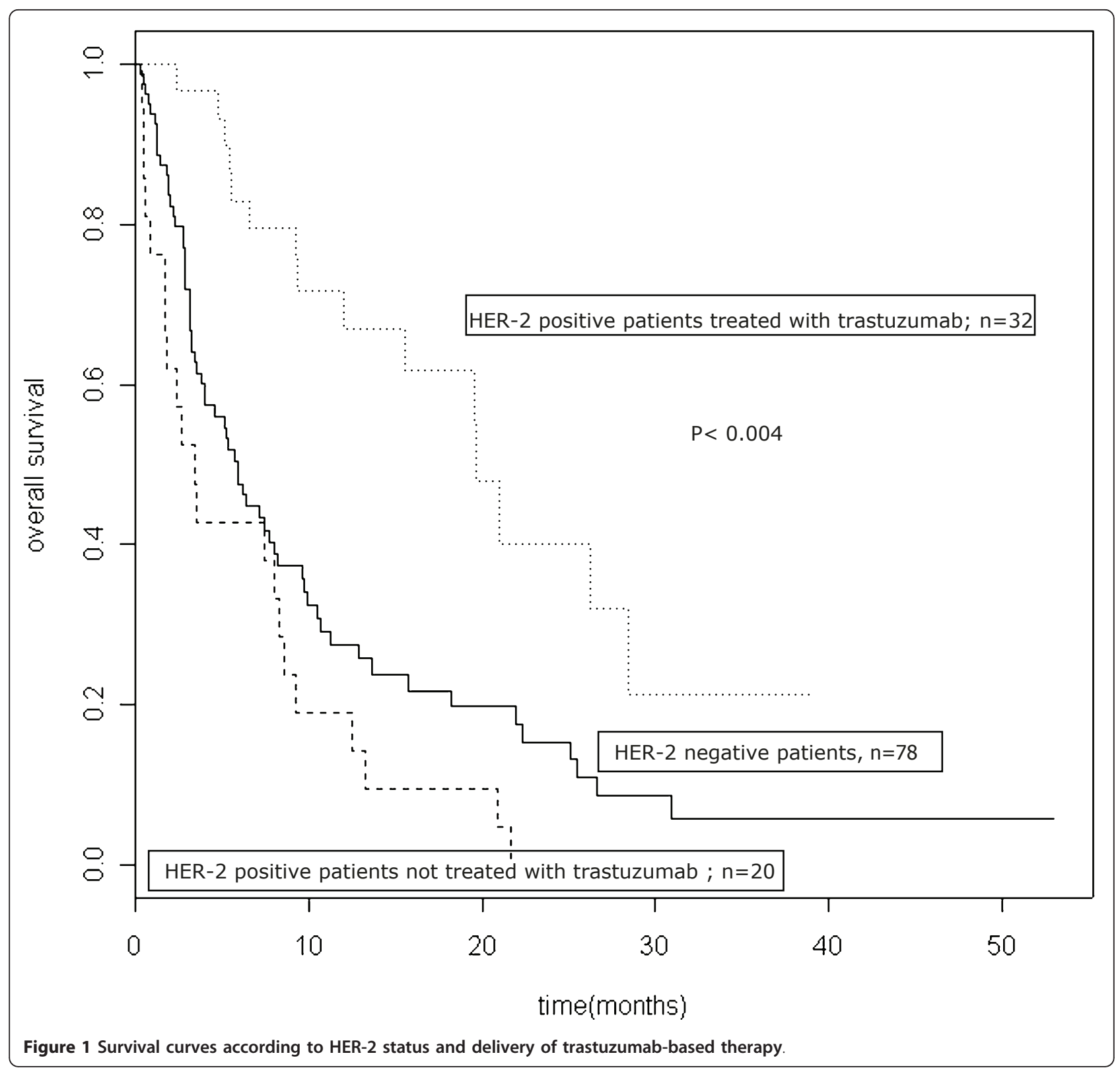

with HER2-positive BC who developed BM, Nam and colleagues reported a median OS of 13 months in 21 patients who received trastuzumab after diagnosis of mCNS disease compared with 4 months in those $(\mathrm{n}=$ 35) who did not receive trastuzumab after diagnosis and 3 months in $70 \mathrm{BM}$ patients with HER2-negative tumors $(\mathrm{p}=0.0011)[26]$. Bartsch and colleagues also analyzed the effect of the continuation of trastuzumab after diagnosis of BM for 17 patients, in comparison with a cohort of 36 pts with HER2 overexpressing tumors not treated with trastuzumab after WBRT [20]. In this report, KPS and trastuzumab were associated with better overall survival, with a trend towards longer time to in- brain progression. Our results confirm the fact that trastuzumab-treated HER2-positive breast cancer patients with BM fare better than HER2-negative breast cancer patients and patients with HER2-positive tumors who do not receive trastuzumab [20-26]. In agreement with three previous reports, this survival advantage for patients with brain metastases from tumors that overexpress HER2 does not seem to be due to an intrinsic biologic advantage of HER2 overexpression, as patients with HER2-overexpressing tumors who did not receive trastuzumab had survival similar to that of patients with tumors that did not overexpress HER2 [23,26,33]. In our experience, about $60 \%$ of HER-2 positive patients 
Table 3 Predictors of overall survival in patients with brain metastases from breast cancer (univariate analyses)

\begin{tabular}{|c|c|c|c|}
\hline Covariate & Comparison & $\begin{array}{c}\text { Hazard Ratio } \\
\text { [Cl 95\%] }\end{array}$ & $\begin{array}{c}P \\
N=130\end{array}$ \\
\hline Age at BM diagnosis & $\geq 50$ Vs. $<50$ & $1.21[0.80 ; 1.81]$ & 0.329 \\
\hline KPS & $\geq 70$ vs. $<70$ & $0.51[0.34 ; 0.77]$ & 0.0013 \\
\hline RTOG RPA class & III vs. I-II & $1.98[1.32 ; 2.98]$ & 0.0013 \\
\hline Time interval (y) between primary tumor and BM diagnosis & $\geq 2$ vs. $<2$ & $3.76[0.52 ; 27.18]$ & 0.968 \\
\hline Brain metastases & Presence of systemic metastases vs. Alone & $1.52[0.62 ; 3.74]$ & 0.366 \\
\hline Visceral metastases & Yes vs No & $1.34[0.84 ; 2.11]$ & 0.2159 \\
\hline Bone metastases & Yes vs No & $1.07[0.71 ; 1.60]$ & 0.745 \\
\hline No. of BM & Multiple vs. single & $1.12[0.41 ; 3.06]$ & 0.822 \\
\hline $\mathrm{Nb}$ of other metastatic sites & Multiple vs. single & $1.516[0.6148 ; 3.74]$ & 0.3627 \\
\hline Histology & lobular and other vs. ductal & $0.77[0.34 ; 1.77]$ & 0.545 \\
\hline Tumor HR status & Negative vs. positive & $1.37[0.91 ; 2.06]$ & 0.127 \\
\hline HER-2 overexpression & Negative vs. positive & $1.48[0.98 ; 2.24]$ & 0.0606 \\
\hline Trastuzumab-based therapy for HER2 overexpressing tumor & Yes vs No & $0.45[0.27 ; 0.75]$ & 0.001631 \\
\hline HR- \& HER2- & Yes vs No & $2.17[1.38 ; 3.43]$ & 0.0006 \\
\hline SBR grade & 3 vs. $1-2$ & $1.59[1.00 ; 2.52]$ & 0.0484 \\
\hline $\mathrm{LDH}(\mathrm{U} / \mathrm{L})$ & $>500$ vs. $\leq 500$ & $2.01[1.27 ; 3.16]$ & 0.0026 \\
\hline Lymphocyte count & $>700$ vs. $\leq 700$ & $0.58[0.37 ; 0.89]$ & 0.0138 \\
\hline Total radiation dose (Gy) & $>30$ vs. $\leq 30$ & $1.54[0.49 ; 4.91]$ & 0.463 \\
\hline
\end{tabular}

Abbreviations: KPS: Karnofsky performance status; HR: hormonal receptor; SBR = Scarff-Bloom-Richardson grade; HR = hormone receptor; RTOG = Radiation

Therapy Oncology Group; RPA = recursive partitioning analysis;

treated with trastuzumab who died apparently succumbed from CNS progression. Similarly, in a retrospective series of 122 patients treated with trastuzumab between 1998 and 2000 at Dana-Farber/Partners Cancer Care, about $50 \%$ of the 21 patients with brain metastases who died apparently succumbed from CNS progression, despite stable or responsive non-CNS disease [34]. These results suggest that HER2 targeting may improve brain metastasis outcomes through durable control of systemic extracranial disease in HER2-positive breast cancer patients [35]. However, one should keep in mind that the determination of the cause of death is difficult in this context. As systemic therapies improve, there is concern that the incidence of symptomatic brain metastases will increase, and that control of CNS disease will become a more vital component of overall disease control and quality of life. Althought the clinical activity of trastuzumab on brain metastases remains debated, trastuzumab may cross the blood-brain barrier when its permeability is increased, as it occurs during WBRT [36]. Preclinical results also found that trastuzumab may act synergistically with radiation in a HER2 level-dependent manner [37], encouraging further assessment in combination with WBRT. Chargari and colleagues reported preliminary results of WBRT with concurrent trastuzumab for treatment of $\mathrm{BM}$ in $31 \mathrm{BC}$ patients [38]. After WBRT, radiologic responses were observed in 23 patients $(74.2 \%)$, including $6(19.4 \%)$ with a complete radiologic response and 17 (54.8\%) with a partial radiologic response. No Grade 2 or greater acute toxicity was observed. The median survival time from the start of WBRT was 18 months [range, 2-65] and the median interval to brain progression was 10.5 months [range, 227]. By dual inhibition of HER1 and HER2, lapatinib also demonstrated a modest efficacy in HER2-positive breast cancer patients with brain metastases [39]. However, Lin et al. found that up to $20 \%$ patients with CNS progression after cranial radiation receiving lapatinib and capecitabine experience an objective response [40]. Lapatinib is currently under investigation in combination with WBRT in an ongoing, phase I trial [41]. A phase II study is also currently assessing the efficacy and

Table 4 Multivariate Analysis of Overall Survival, Cox Model $(n=130$ )

\begin{tabular}{|c|c|c|c|}
\hline Covariate & Comparison & $\begin{array}{c}\text { Hazard Ratio for death } \\
\text { [Cl 95\%] }\end{array}$ & $\begin{array}{c}\mathrm{P} \\
\mathrm{N}=127\end{array}$ \\
\hline HER-2 positive patients treated with trastuzumab & Yes vs No & $0.49[0.29 ; 0.83]$ & 0.00810 \\
\hline KPS & $\geq 70$ vs. $<70$ & $0.56[0.37 ; 0.85]$ & 0.00578 \\
\hline
\end{tabular}


safety of concurrent WBRT and capecitabine followed by combination capecitabine and sunitinib for treatment of brain metastases from breast cancer [42]. Concurrent chemoradiation is also currently being investigated with the aim of improving the control rate of both cerebral and systemic disease $[39,43]$. Regarding WBRT fractionation, several trials have examined the influence of the dose, timing and fractionation of WBRT, without identifying a clearly superior schedule [11]. The most widely used WBRT regimen delivers 30 Gy in ten 3-Gy fractions, but this may be inadequate for long-term tumor control. Li et al. recently examined the outcomes of 208 patients who received WBRT as 10 daily 3-Gy fractions in the control arm of the PCI-P120-9801 phase III trial of motexafin gadolinium [44]. Neurocognitive function (NCF) and survival were compared in 135 patients assessable at 2 months with tumor shrinkage below (poor responders) and above (good responders) the population median (45\%) on MRI. Good responders survived significantly longer than poor responders (median $300 \pm 26$ vs $240 \pm 19$ days; $\mathrm{p}=.03$ ), and had a longer median time before NCF deterioration, supporting the use of techniques to maximize intracranial control, particularly for patients with HER-2-overexpressing tumors treated with trastuzumab. In our experience, BM patients with HER-2 overexpressing tumors treated with trastuzumab can expect a median overall survival time of about 20 months and a 1-year survival rate of about $60 \%$. This subgroup of patients may therefore have a higher risk of experiencing late radiation-related toxicity such as neurocognitive dysfunction, and might benefit from longer-course WBRT with lower doses per fraction [45]. Further studies of more aggressive local therapy with different dose and fractionation schedules, in a manner that could minimize late effects, could probably be more efficient for this subgroup of patients supposed to have longest median survival.

The combination of a tumor type that has a high potential for CNS spread and a treatment that does not penetrate the CNS but is very effective outside of the CNS creates the opportunity for CNS disease to become a major clinical problem. As an example, the introduction of trastuzumab has altered the natural history of patients with HER2-positive breast cancer, and unmasked CNS metastases as a potential sanctuary site. It is anticipated that this HER2 paradigm is applicable across tumor types, as patients live longer with advanced cancer. In the next decade, there will be a greater need to conduct carefully designed trials of both cytotoxic chemotherapeutic agents and targeted agents, either alone, or in combination, with specific CNS end points.

\section{Conclusions}

In conclusion, BM patients with breast cancer are an heterogenous group of patients. BM patients with HER2 overexpressing tumors treated by trastuzumab appears to be a clearly distinct subroup of patients who can expect a median survival time of about 20 months and a1-year survival rate of $60 \%$. This information may be useful to tailor the therapy for subgroups of patients, to define homogeneous cohorts for prospective randomized trials, and to identify more precisely patients with relative good prognosis who could be treated with innovative approaches, in order to obtain better intra cerebral control, in a manner that could minimize late effects.

\section{Author details}

'Department of Radiation Oncology, Centre Hospitalier Privé Saint Grégoire, Saint Grégoire, France. Departments of Radiation Oncology, Institut CurieHôpital René Huguenin, Saint Cloud, France. ${ }^{3}$ Medical Statistics, Institut Curie-Hôpital René Huguenin, Saint Cloud, France. ${ }^{4}$ Medical Oncology, Institut Curie-Hôpital René Huguenin, Saint Cloud, France. ${ }^{5}$ Radiology, Institut Curie-Hôpital René Huguenin, Saint Cloud, France. 'Department of Medical Oncology, Institut Gustave Roussy, Villejuif, France.

\section{Authors' contributions}

RLS and CM designed coordinated the study and drafted the wrote the manuscript. $L$ and EMF performed the statistical analysis. MG, YK PC, JG and $\mathrm{AL}$ participated in its design and coordination and helped draft the manuscript. All authors read and approved the final manuscript.

\section{Conflict of interest statement}

The authors indicate no potential conflict of interest.

Received: 7 February 2011 Accepted: 19 September 2011 Published: 19 September 2011

\section{References}

1. Lin NU, Bellon JR, Winer EP: CNS metastases in breast cancer. J Clin Oncol 2004, 22:3608-17.

2. Bendell JC, Domchek SM, Burstein HJ, et al: Central nervous system metastases in women who receive trastuzumab-based therapy for metastatic breast carcinoma. Cancer 2003, 97:2972-7.

3. Burstein HJ, Lieberman G, Slamon DJ, Winer EP, Klein P: Isolated central nervous system metastases in patients with HER2-overexpressing advanced breast cancer treated with first-line trastuzumab-based therapy. Ann Oncol 2005, 16:1772-7.

4. Clayton AJ, Danson S, Jolly S, et al: Incidence of cerebral metastases in patients treated with trastuzumab for metastatic breast cancer. $\mathrm{Br} J$ Cancer 2004, 91:639-43.

5. Gabos Z, Sinha R, Hanson J, et al: Prognostic Significance of Human Epidermal Growth Factor Receptor Positivity for the Development of Brain Metastasis After Newly Diagnosed Breast Cancer. J Clin Oncol 2006, 24:5658-63.

6. Lower EE, Glass E, Blau R, Harman S: HER-2/neu expression in primary and metastatic breast cancer. Breast Cancer Res Treat 2009, 113:301-6.

7. Miller KD, Weathers T, Haney LG, et al: Occult central nervous system involvement in patients with metastatic breast cancer: prevalence, predictive factors and impact on overall survival. Ann Oncol 2003, 14:1072-7.

8. Shmueli $\mathrm{E}$, Wigler $\mathrm{N}$, Inbar M: Central nervous system progression among patients with metastatic breast cancer responding to trastuzumab treatment. Eur J Cancer 2004, 40:379-82.

9. Slimane $K$, Andre F, Delaloge $S$, et al: Risk factors for brain relapse in patients with metastatic breast cancer. Ann Oncol 2004, 15:1640-4. 
10. Fokstuen T, Wilking N, Rutqvist LE, et al: Radiation therapy in the management of brain metastases from breast cancer. Breast Cancer Res Treat 2000, 62:211-6.

11. Khuntia D, Brown P, Li J, Mehta MP: Whole-brain radiotherapy in the management of brain metastasis. J Clin Oncol 2006, 24:1295-304

12. Lentzsch $S$, Reichardt $P$, Weber F, Budach $V$, Dorken B: Brain metastases in breast cancer: prognostic factors and management. Eur J Cancer 1999, 35:580-5.

13. Gaspar L, Scott C, Rotman M, et al: Recursive partitioning analysis (RPA) of prognostic factors in three Radiation Therapy Oncology Group (RTOG) brain metastases trials. Int J Radiat Oncol Biol Phys 1997, 37:745-51.

14. Le Scodan R, Massard C, Mouret-Fourme E, et al: Brain metastases from breast carcinoma: validation of the radiation therapy oncology group recursive partitioning analysis classification and proposition of a new prognostic score. Int J Radiat Oncol Biol Phys 2007, 69:839-45.

15. Lagerwaard FJ, Levendag PC, Nowak PJ, et al: Identification of prognostic factors in patients with brain metastases: a review of 1292 patients. Int $J$ Radiat Oncol Biol Phys 1999, 43:795-803.

16. Lorenzoni J, Devriendt D, Massager $N$, et al: Radiosurgery for treatment of brain metastases: estimation of patient eligibility using three stratification systems. Int J Radiat Oncol Biol Phys 2004, 60:218-24.

17. Rades D, Dunst J, Schild SE: A new scoring system to predicting the survival of patients treated with whole-brain radiotherapy for brain metastases. Strahlenther Onkol 2008, 184:251-5.

18. Sperduto PW, Berkey B, Gaspar LE, Mehta M, Curran W: A new prognostic index and comparison to three other indices for patients with brain metastases: an analysis of 1,960 patients in the RTOG database. Int $J$ Radiat Oncol Biol Phys 2008, 70:510-4.

19. Weltman E, Salvajoli JV, Brandt RA, et al: Radiosurgery for brain metastases: a score index for predicting prognosis. Int J Radiat Oncol Biol Phys 2000, 46:1155-61.

20. Bartsch R, Rottenfusser A, Wenzel C, et al: Trastuzumab prolongs overall survival in patients with brain metastases from Her2 positive breast cancer. J Neurooncol 2007, 85:311-7.

21. Dawood S, Broglio K, Esteva FJ, et al: Defining prognosis for women with breast cancer and CNS metastases by HER2 status. Ann Oncol 2008 , 19:1242-8

22. Eichler AF, Kuter I, Ryan $P$, et al: Survival in patients with brain metastases from breast cancer: the importance of HER-2 status. Cancer 2008, 112:2359-67.

23. Kirsch DG, Ledezma CJ, Mathews CS, et al: Survival after brain metastases from breast cancer in the trastuzumab era. J Clin Oncol 2005, 23:2114-6.

24. Melisko ME, Glantz M, Rugo HS: New challenges and opportunities in the management of brain metastases in patients with ErbB2-positive metastatic breast cancer. Nat Clin Pract Oncol 2009, 6:25-33.

25. Park BB, Uhm JE, Cho EY, et al: Prognostic factor analysis in patients with brain metastases from breast cancer: how can we improve the treatment outcomes? Cancer Chemother Pharmacol 2009, 63:627-33.

26. Nam BH, Kim SY, Han HS, et al: Breast cancer subtypes and survival in patients with brain metastases. Breast Cancer Res 2008, 10:R20.

27. Kaplan EL, Meier P: Nonparametric estimation from incomplete observations. J Am Stat Assoc 1958, 53:457-81.

28. Chang J, Clark GM, Allred DC, et al: Survival of patients with metastatic breast carcinoma: importance of prognostic markers of the primary tumor. Cancer 2003, 97:545-53.

29. Engel J, Eckel $R$, Aydemir $U$, et al: Determinants and prognoses of locoregional and distant progression in breast cancer. Int J Radiat Oncol Biol Phys 2003, 55:1186-95.

30. Barnholtz-Sloan JS, Sloan AE, Davis FG, et al: Incidence proportions of brain metastases in patients diagnosed (1973 to 2001) in the Metropolitan Detroit Cancer Surveillance System. J Clin Oncol 2004, 22(14):2865-72.

31. Gonzalez-Angulo AM, Cristofanilli M, Strom EA, et al: Central nervous system metastases in patients with high-risk breast carcinoma after multimodality treatment. Cancer 2004, 101(8):1760-6.

32. Pestalozzi $B C$, Zahrieh $D$, Price $K N$, et al: Identifying breast cancer patients at risk for Central Nervous System (CNS) metastases in trials of the International Breast Cancer Study Group (IBCSG). Ann Oncol 2006, 17(6):935-44, Epub 2006 Apr 7.
33. Church DN, Modgil R, Guglani S, et al: Extended survival in women with brain metastases from HER2 overexpressing breast cancer. Am J Clin Oncol 2008, 31(3):250-4.

34. Bendell JC, Domchek SM, Burstein HJ, et al: Central nervous system metastases in women who receive trastuzumab-based therapy for metastatic breast carcinoma. Cancer 2003, 97:2972-7.

35. Park YH, Park MJ, Ji SH, et al: Trastuzumab treatment improves brain metastasis outcomes through control and durable prolongation of systemic extracranial disease in HER2-overexpressing breast cancer patients. Br J Cancer 2009, 100:894-900.

36. Stemmler $\mathrm{H}-J$, Schmitt M, Willems A, et al: Ratio of trastuzumab levels in serum and cerebrospinal fluid is altered in HER2-positive breast cancer patients with brain metastases and impairment of blood-brain barrier. Anticancer Drugs 2007, 18:23-28.

37. Liang $K, L u Y$, Jin $W$, et al: Sensitization of breast cancer cells to radiation by trastuzumab. Mol Cancer Ther 2003, 2:1113-20.

38. Chargari C, Idrissi HR, Pierga JY, et al: Preliminary Results of Whole Brain Radiotherapy with Concurrent Trastuzumab for Treatment of Brain Metastases in Breast Cancer Patients. Int J Radiat Oncol Biol Phys 2010.

39. Pieńkowski T, Zielinski CC: Trastuzumab treatment in patients with breast cancer and metastatic CNS disease. Ann Oncol 2010, 21(5):917-24, Epub 2009 Aug 28.

40. Lin NU, Diéras $V$, Paul D, et al: Multicenter phase II study of lapatinib in patients with brain metastases from HER2-positive breast cancer. Clin Cancer Res 2009, 15:1452-9.

41. [http://clinicaltrials.gov/ct2/show/NCT00470847].

42. [http://clinicaltrials.gov/ct2/show/NCT00570908].

43. Cassier PA, Ray-Coquard I, Sunyach MP, et al: A phase 2 trial of wholebrain radiotherapy combined with intravenous chemotherapy in patients with brain metastases from breast cancer. Cancer 2008, 113(9):2532-8

44. Li J, Bentzen SM, Renschler M, et al: Regression after wholebrain radiation therapy for brain metastases correlates with survival and improved neurocognitive function. J Clin Oncol 2007, 25:1260-1266.

45. DeAngelis LM, Delattre JY, Posner JB: Radiation-induced dementia in patients cured of brain metastases. Neurology 1989, 39:789-96.

\section{Pre-publication history}

The pre-publication history for this paper can be accessed here: http://www.biomedcentral.com/1471-2407/11/395/prepub

doi:10.1186/1471-2407-11-395

Cite this article as: Le Scodan et al: Brain metastases from breast cancer: prognostic significance of HER-2 overexpression, effect of trastuzumab and cause of death. BMC Cancer 2011 11:395.

\section{Submit your next manuscript to BioMed Central and take full advantage of:}

- Convenient online submission

- Thorough peer review

- No space constraints or color figure charges

- Immediate publication on acceptance

- Inclusion in PubMed, CAS, Scopus and Google Scholar

- Research which is freely available for redistribution

Submit your manuscript at www.biomedcentral.com/submit
C Biomed Central 